\title{
As Tecnologias da Informação e Comunicação e o Design de Serviços em Cuba: Um estudo de caso sobre o Pacote Semanal
}

\author{
Information and Communication Technologies and Service Design in Cuba: A Case \\ Study on the Weekly Package
}

\author{
ARGUELLES, Yanet; MSc.; Universidade de Brasília \\ yanetca00@gmail.com \\ KALUME, Ana Carolina; DSc; Universidade de Brasília \\ ckalume@gmail.com \\ CÂMARA, Rogério; DSc; Universidade de Brasília \\ rogeriojcamara@gmail.com
}

\section{Resumo}

Em Cuba, devido às limitações tecnológicas e de acesso à internet, a população criou soluções inovadoras para obter informações localizadas nas redes. Esta nova forma de acesso à informação é chamada de Pacote Semanal (PS), compêndio de informações que abrange diferentes tipos de conteúdos digitais. Com o crescimento do PS e da quantidade de pessoas que implementaram sua venda como negócio, surgiu a concorrência entre os vendedores, empregando o design de serviços como modo de ganhar clientes. O presente trabalho tem como objetivo analisar o fluxo de circulação do PS em uma pesquisa que envolve analises qualitativa e quantitativa, como forma de identificar quem são, como produzem e as preferências informacionais dos que adquirem este tipo de serviço, na cidade de Santa Clara, em Cuba. Diante da restrição de acesso à informação no país, o PS apresenta-se como um recurso com grande aceitação e ampla usabilidade entre os cidadãos cubanos.

Palavras Chave: Cuba; Pesquisa Qualitativa e Quantitativa, Design de Serviços.

\begin{abstract}
In Cuba, due to technological limitations and Internet access, the population has created innovative solutions to obtain information located in the networks, this new form of access to information is called the Weekly Package (PS), being a compendium of information that covers different types digital content. With the growth of the PS and the number of people who have implemented its sale as a business, competition has arisen among sellers, employing service design as a way to gain customers. The objective of this study is to analyze the circulation flow of PS in a research that involves qualitative and quantitative analysis, as a way of identifying who they are, how they produce, and the informational preferences of those who acquire this type of service in the city of Santa Clara, in Cuba. Given the restriction of access to information in the country, the PS presents itself as a resource with great acceptance and wide usability among Cuban citizens.
\end{abstract}

Keywords: Cuban; Qualitative and Quantitative Research; Service Design. 


\section{Introdução}

Em Cuba, devido a causas econômicas e de infraestrutura, o acesso à internet é dificultado, existindo baixa conectividade, preços elevados e reduzida oferta aos consumidores, que advém de apenas uma Empresa de Telecomunicações no pais, a ETECSA, que oferece serviços limitados de conectividade, porém, o custo do tempo de conexão é elevado para o salário do trabalhador cubano (MINCOM, 2018). Em geral, a população não tem conexão em casa, nem mobilidade de acesso via smartphones. Além disso, a internet tem pontos específicos nas cidades de Cuba, tais como Santa Clara (pertencentes à província de Villa Clara), nas quais é possível se conectar por meio de um sinal wifi local, no entanto a velocidade da rede é lenta. Com as dificuldades de acesso às informações disponíveis na internet, a população cubana tem criado formas alternativas de acesso, tais como o uso de pendrives e HD externos, como meios de obtenção de informação e compartilhamento.

Sendo assim, empreendedores cubanos, desenvolveram variantes de inovação social, criação e difusão de informações. O método mais usado em Cuba, hoje, denomina-se "Pacote Semanal" (PS), um conjunto de dados comercializados semanalmente junto à população. Segundo (Concepción, 2015a), o "Pacote Semanal" "surge como uma alternativa para as circunstâncias desfavoráveis de dois meios: televisão e internet" e representa "um compêndio de materiais que abrange todos os tipos de propostas, desde os mais variados gêneros televisivos e cinematográficos até aplicativos informáticos" (CONCEPCIÓN, 2015b).

A distribuição do PS, como o nome indica, é semanal. O conteúdo não sofre muitas variações de uma semana para outra, procura-se dar continuidade aos conteúdos audiovisuais publicados no pacote da semana anterior, assim como atualizações de softwares e antivírus. A quantidade de informação compreendida neste conjunto alcança até um terabyte de capacidade.

As informações do pacote resultam do trabalho de uma equipe chamada Matriz del Paquete Semanal, com acesso à internet e vários equipamentos tecnológicos que lhes permitem fazer o download das informações. Resultam ainda da realização de cópias de vídeos através de antenas parabólicas de televisão ${ }^{1}$, além de produções independentes que encontram no pacote semanal um mercado. Estes pacotes semanais e seus modos de circulação são objetos do presente artigo, desenvolvido sob a perspectiva do design de serviço, a partir de pesquisas realizadas no Consejo Popular Condado Norte, localizado no município de Santa Clara, capital da província de Villa Clara, Cuba, no centro do país. O Consejo Popular é o órgão mais diretamente ligado aos cidadãos e aos centros laborais; atua num determinado território e apoia os órgãos do Poder Popular municipal, provincial e nacional (CONSEJO POPULAR - ECURED, [S.d.]).

Partindo do contexto apresentado, busca-se analisar os canais de distribuição e as preferências no que diz respeito a conteúdos digitais, dos consumidores do pacote semanal na cidade de Santa Clara, a partir de uma pesquisa de métodos mistos, envolvendo análises qualitativas e quantitativas e a metodologia básica do design de serviços, para a compreensão sobre o funcionamento deste fenômeno nacional, na República de Cuba.

\footnotetext{
${ }^{1}$ Informação obtida a partir de entrevista realizada com um dos criadores do pacote semanal.
} 


\section{Procedimentos Metodológicos}

Para a realização desta pesquisa foi elaborado um estudo que parte da junção entre pesquisa qualitativa e quantitativa em diferentes fases do processo, com vistas a um estudo de caso, com coleta de dados a partir de observação participante, entrevistas em profundidade e aplicação de instrumentos de coleta de dados. Para a aplicação destes instrumentos, assim como a realização das análises e discussão dos resultados, foi seguido o caminho metodológico proposto por Ana Carolina Kalume Maranhão, (2017), o qual é apresentado na Figura 1, a seguir.

Figura 1- Passos metodológicos seguidos na pesquisa

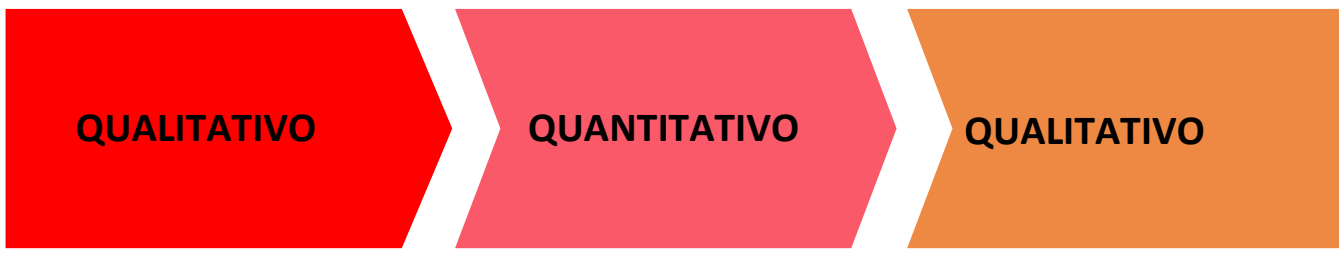

Fonte: Modificado de (Maranhão, 2017).

A investigação foi concebida em três fases, como apresentado na Figura 1, sendo que a primeira fase é composta pela abordagem metodológica qualitativa e inclui a definição da unidade de caso, elaboração e aplicação dos instrumentos da coleta de dados e aplicação das ferramentas do design de serviço. Na segunda fase, foi empregada a abordagem metodológica quantitativa, que consistiu na aplicação e análise estatística do instrumento de coleta de dados. Na última fase, foram realizadas análises qualitativas dos resultados. Estas fases indicam o processo de concepção e execução da pesquisa, o que será detalhado nos tópicos seguintes.

\subsection{Seleção da amostra}

Na primeira fase, mapeou-se o público-alvo a partir de observação participante, como forma de selecionar a população que seria pesquisada na cidade de Santa Clara. Como recorte, entre os 19 Consejos Populares do Município, foi escolhido o Consejo Popular Condado Norte, por ser uma área popularmente conhecida como a mais comercial da cidade, tanto de negócios lícitos quanto ilícitos. Também por meio da observação e sondagem da comunidade, foi possível detectar cinco vendedores do PS com os quais foram realizadas entrevistas em profundidade combinada com entrevistas contextuais, como forma de identificar quais atores estavam envolvidos no processo de produção e comercialização do pacote semanal.

Das entrevistas com os vendedores, foram mapeados três paqueteros ${ }^{2}$. Além disto, também, nesta fase, foi possível identificar os criadores do PS, que moram em Havana, capital do país. Os métodos de coleta de dados e as ferramentas de design de serviços foram aplicadas em uma amostra escolhida por conveniência, dada a dificuldade em acessar todo o universo de clientes que consome os produtos comercializados no PS.

Esta amostra é composta por: dois criadores do pacote semanal, três paqueteros e cinco vendedores. Somados a isto, também fazem parte do contexto de investigação da pesquisa 50 clientes-usuários do pacote semanal, compondo o seguinte universo: dez clientes-usuários de

\footnotetext{
${ }^{2}$ São os indivíduos que recebem e distribuem o Pacote Semanal nas províncias.
} 
cada uns dos cinco vendedores entrevistados, conforme apresenta a figura 3.

Figura 3- Amostra do caso de estudo

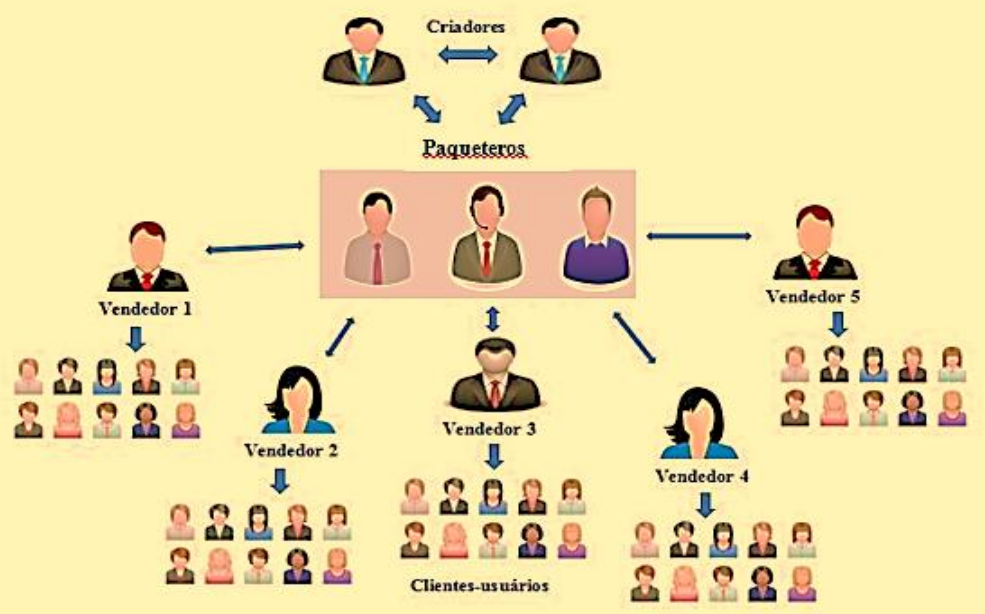

Fonte: Elaboração dos autores.

Todas as perguntas para a coleta de dados foram elaboradas segundo a metodologia dos processos básicos do design de serviços, expostas em This is service design thinking, (STICKDORN \& SCHNEIDER, 2011). Esta metodologia é composta por quatro etapas: exploração, criação, reflexão e implementação, que permeiam as muitas fases da pesquisa, dado que cada uma das etapas propõe aspectos a medir, partindo das quais foram concebidas as perguntas dos instrumentos da coleta de dados.

Segundo Stickdorn e Schneider (2011), a metodologia básica do design de serviço apresenta-se como uma caixa de ferramentas. Para a presente pesquisa, foram empregadas duas ferramentas do processo básico do design de serviços, correspondendo à etapa de exploração. Uma delas é o mapa de stakeholders, para a identificação de todas as partes implicadas no pacote semanal, e a outra, as entrevistas contextuais, com vistas a ajudar o entrevistado a se lembrar de detalhes específicos do que está sendo investigado. Além disto, desde a etapa de criação, foram empregados os princípios da cocriação para interpretar a composição dos CDs do PS, e os processos de prestação do serviço de compra-venda.

$\mathrm{Na}$ segunda fase, foram aplicados os instrumentos de coleta de dados a 50 clientes/usuários da amostra selecionada. O formulário utilizado na coleta de dados foi composto por 12 questões referentes ao acesso e ao uso do pacote semanal de conteúdos digitais. Três das questões do formulário (questões 1, 11 e 12) têm possibilidade de resposta aberta. A aplicação foi realizada entre os dias 16 a 26 de janeiro de 2017. Os entrevistados não eram identificados, para que se sentissem livres para escrever com mais transparência.

As análises das questões foram quantitativas univariadas, a partir de uma base de dados que permitisse a visualização das respostas obtidas e através de elaboração de gráficos e tabelas, com resultados quantitativos das variáveis do questionário. Após a análise quantitativa, foram feitas análises descritivas das respostas. O gerenciamento da base de dados e as análises descritivas foram realizados por meio do Microsoft Excel 2013. 
Por fim, na terceira e última fase da pesquisa, foi realizada a avaliação dos resultados obtidos da coleta de dados, de forma descritiva. Para tanto seguiram-se três passos: redução da informação, disposição e transformação da informação e interpretação da informação (SAMPIERI, et al., 2014). Procurou-se abreviar a quantidade das informações resultantes da coleta de dados, para facilitar a análise, compreendidas e relevantes, incluindo a separação, classificação e síntese de toda a informação. Na sequência, foram organizados os dados, para que o processamento fosse viável.

\section{Análise dos resultados}

A observação participante permitiu identificar quem eram os vendedores do pacote semanal e dos conteúdos digitais. É possível afirmar que a cada três quadras existem vendedores, conhecidos popularmente em espanhol como llenadores de memorias ${ }^{3}$. Estes vendedores exercem a atividade como negócio particular, e não existe nenhum padrão geográfico para a localização dos mesmos, nem um perfil estabelecido, pois existem vendedores que, além do negócio do pacote, apresentam vínculo empregatício com o governo, e vendedores que só se dedicam a este tipo de atividade. Foi possível detectar também quem são os clientes/usuários de cada vendedor, determinando que os clientes escolhem seus fornecedores pela qualidade do serviço recebido e não pela proximidade. Nem todos os usuários do PS são precisamente clientes, isto é, a maior parte dos usuários do pacote semanal compra os conteúdos, porém tem uma minoria que obtém as informações por meio de compartilhamento, entre colegas e vizinhos, gerando, assim, uma rede social em meio à comunidade. Também foi possível detectar, por meio de entrevistas realizadas, que a mobilidade dos distribuidores do PS é realizada em transportes da rede pública e, em poucas ocasiões, em transportes particulares, ou seja, o distribuidor viaja para as províncias em ônibus interprovinciais.

É possível afirmar ainda que os principais elementos culturais da amostra selecionada são representados por pessoas de natureza sociável, que formam com os vizinhos uma grande família. Uma comunidade de muitos negócios, conhecida como a mais comercial da cidade, embora seja uns dos bairros menos desenvolvidos. O Condado Norte caracteriza-se por ampla cultura popular, com uma área de ensaio para carnavais e dois grupos de dança que representam a comunidade todos os anos em competições de carnaval. A religião mais praticada é a Santeria, proveniente da cultura africana e conservada por tradição. A língua falada pela população é o espanhol, como em todo país. No entanto, os vizinhos do Condado costumam expressar-se por meio de gírias e jargões, às vezes difíceis de serem entendidos por quem vem de fora deste contexto.

Também por meio da observação foram escolhidos cinco vendedores do PS. Estes vendedores foram entrevistados, por meio de entrevistas em profundidade. Como resultado, foi possível conhecer outros atores envolvidos no pacote semanal, conforme é apresentado abaixo:

1. Criadores do Pacote Semanal: Pessoas que realizam o compêndio de informações que integram o pacote semanal, fazem o download dos conteúdos digitais e separam-nos em pastas genéricas. Estas pessoas vivem na capital do país e distribuem o pacote para toda as províncias.

2. Distribuidores 1: São membros da matriz e distribuem o pacote semanal em Havana.

\footnotetext{
${ }^{3}$ Enchedores de pendrive.
} 
3. Distribuidores 2: Distribuem o PS por todas as províncias de Cuba.

4. Recebedor: Recebe o PS ao chegar a cada província e leva para os paqueteros. No caso deste caso de estudo, são três paqueteros na cidade de Santa Clara.

5. Paqueteros: Modificam o pacote semanal de acordo com elementos identitários e vendem para os vendedores.

6. Vendedores (Ilenadores de memorias): Ficam na base, nas comunidades, vendem para os clientes/usuários, tanto o pacote todo como parte dos conteúdos digitais

7. Clientes/usuários: Pessoas que consomem as informações do PS.

A identificação dos principais atores do pacote semanal permitiu a compreensão do papel de cada ator envolvido no processo do PS, assim como o fluxo de circulação para o estudo de caso na cidade estudada. Este fluxo de circulação ajudou a entender a rede de venda do PS e dos conteúdos digitais, pois como uma rede comercial os próprios membros da cadeia atuam como clientes e como provedores, simultaneamente. Assim, os criadores, ao serem os primeiros na rede comercial, atuam só como provedores. Já os recebedores, paqueteros e vendedores, atuam não só como provedores, mas também como clientes. Na figura 1, que segue abaixo, é apresentado o fluxo de circulação do pacote semanal.

Figura 1- Fluxo de circulação

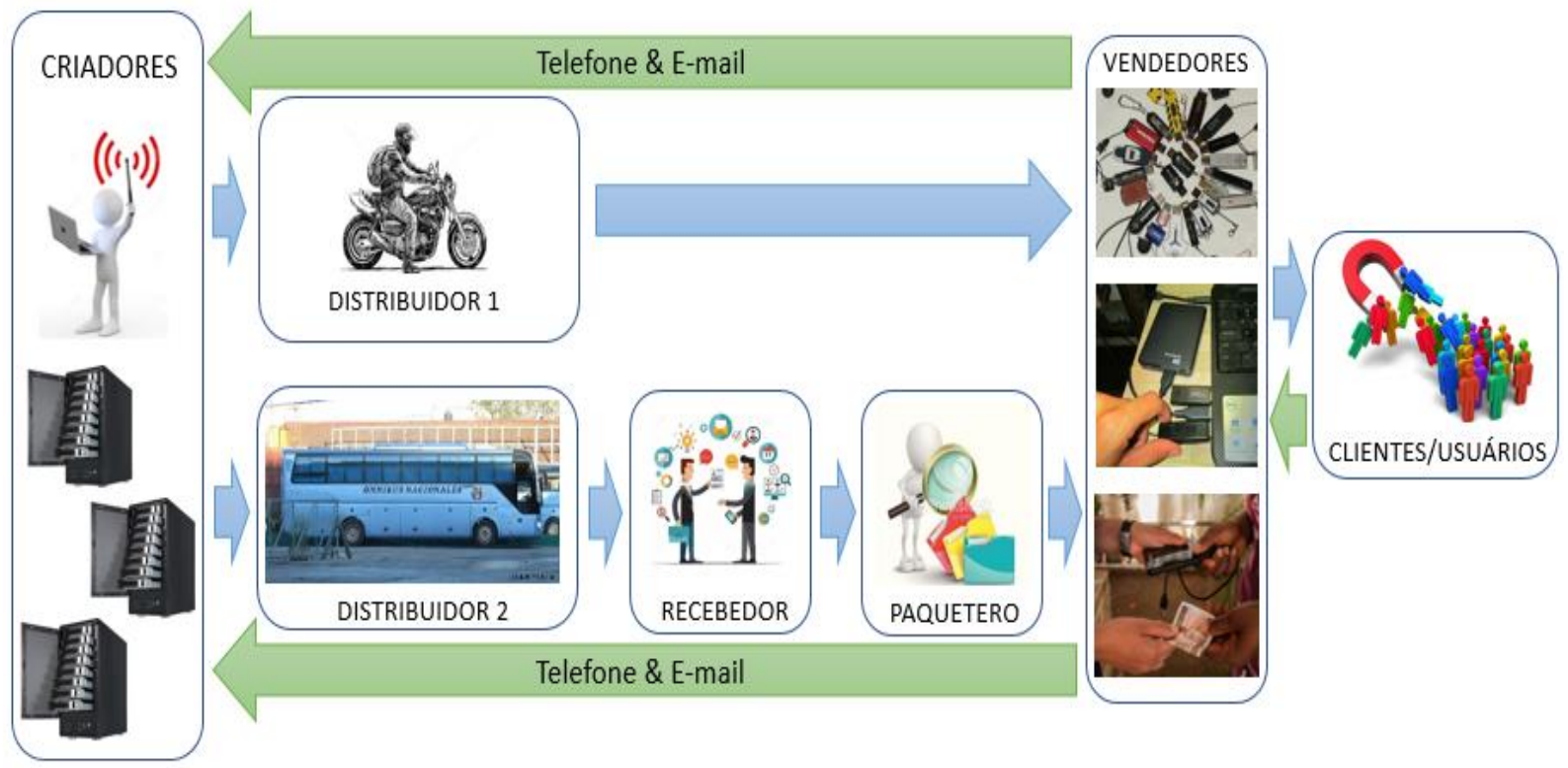

Fonte: Elaboração dos autores.

No fluxo de circulação do pacote semanal, estão expostas linhas em duas direções opostas, o canal azul é o caminho de distribuição do PS, dos criadores aos clientes/usuários. As setas verdes indicam o feedback das informações, conforme as solicitações dos clientes/usuários. Os canais de comunicação para o feedback podem ocorrer no processo comunicacional de individuo para individuo, ou por telefones e e-mail. Temos como primeiro elemento os criadores, que repassam o pacote semanal a distribuidores de dois níveis, o distribuidor 1 (motoqueiro), que reparte o PS direto aos vendedores da cidade de Havana (Cuba) e estes a seus clientes. Enquanto o distribuidor 
2 leva o pacote até as províncias, onde há os receptadores que entregam aos paqueteros, - três no caso da província de Santa Clara-até chegar ao destino final: clientes e usuários.

Com o mapeamento dos atores do empreendimento, todos os grupos de interesse e stakeholders envolvidos no processo de concepção e comercialização foram identificados, como participantes diretos: i) criadores, ii) distribuidores, iii) recebedor e iv) os chamados paqueteros, responsáveis pelo recebimento do produto em cada cidade de origem, para posterior repasse e venda aos usuários. Como atores indiretos na produção do PS, foram identificadas: i) TICs, ii) comunidade e sociedade, iii) entidades governamentais, iv) instituições políticas e $v$ ) empresas públicas. Todas estas informações foram analisadas de forma qualitativa na pesquisa proposta. llustra-se, na figura 2, o mapa de stakeholders.

Figura 2- Mapa de stakeholder

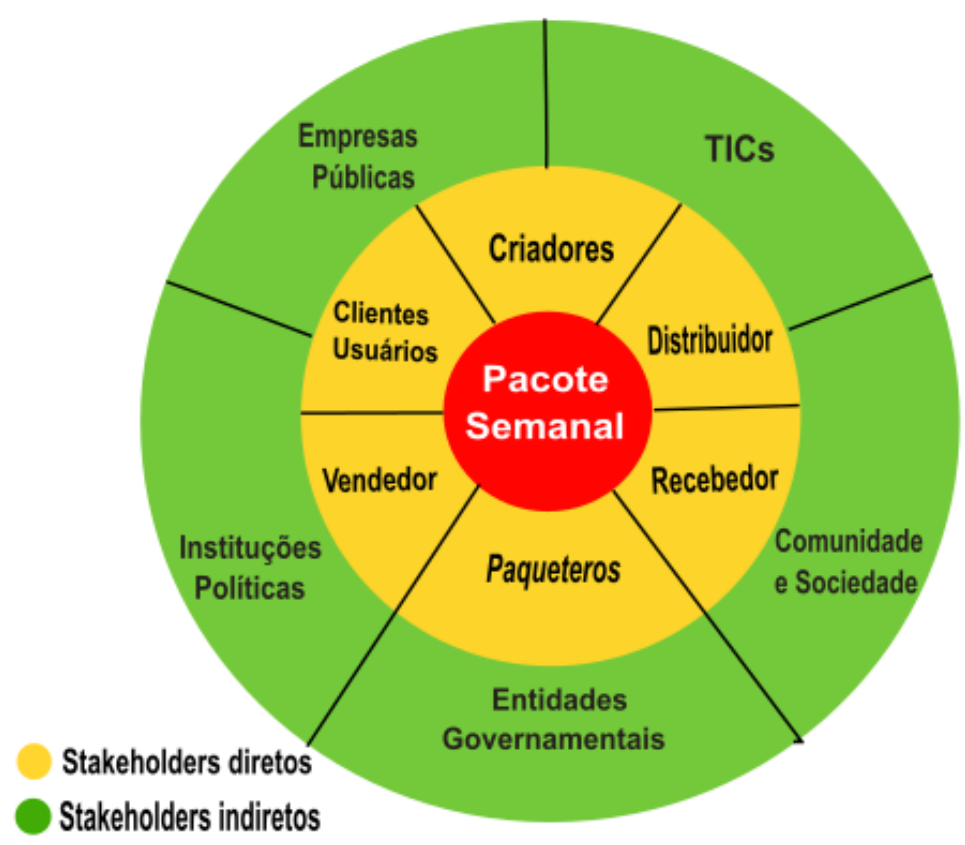

Fonte: Elaboração dos autores.

O mapa de stakeholders representa visualmente os grupos de interesses. Descreve três níveis: o pacote semanal, os agentes diretos e os agentes indiretos. Ambas partes interessadas, diretas e indiretas, interagem entre si durante todo o sistema de produção, circulação e consumo deste meio alternativo. Assim, com a identificação dos grupos de interesse e levando em conta as caraterísticas culturais da amostra selecionada, foram interpretados os resultados coletados nos questionários e realizada uma análise quantitativa univariada. A primeira questão teve como objetivo conhecer a necessidade de uso do PS pela população cubana. No gráfico 1, é apresentado o comportamento da variável necessidade de uso. 
Gráfico 1- “O pacote semanal é necessário para a população cubana? ”

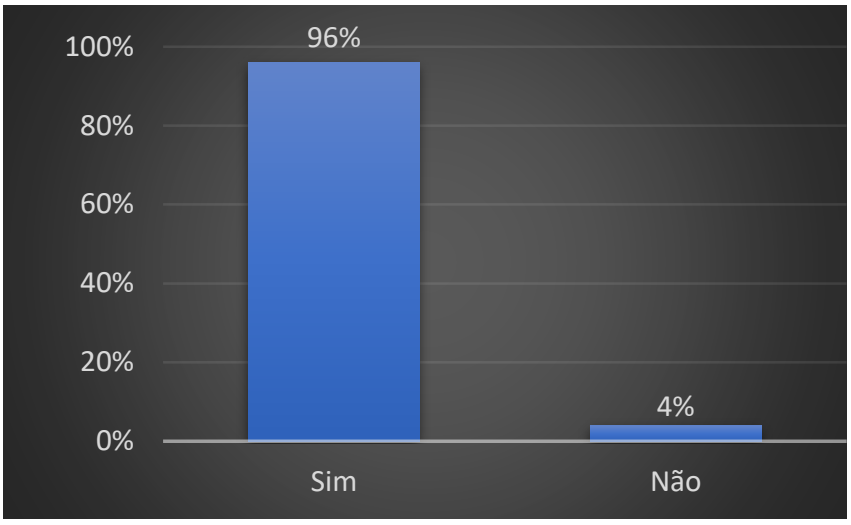

Fonte: Elaboração dos autores.

Praticamente todos os entrevistados consideram o pacote semanal necessário à população cubana. Apenas dois respondentes discordam de tal afirmação, o que equivale a $4 \%$ da amostra coletada. Em contraposição, as 48 pessoas que consideram importante argumentaram que precisam do pacote porque é a via mais fácil para adquirir as informações que se encontram na internet. Tal informação permite definir que o PS ocupa um espaço importante no cotidiano da população cubana.

Visando a identificar as escolhas informacionais dos consumidores, foi elaborada uma questão sobre as preferências de consumo do PS, a qual permitiu que os entrevistados selecionassem mais de uma opção, considerando alguns conteúdos digitais inseridos no pacote, a saber:

- Entretenimentos.

- Aplicativos para celular.

- Documentários.

- Antivírus.

- Esportes.

- Revolico. ${ }^{4}$

- Software.

- Revistas

No gráfico 2, pode-se observar como foi a manifestação das respostas. Quase a totalidade dos entrevistados (96\%) afirma que uma das principais informações do pacote e suas preferências é o entretenimento. Os aplicativos para celular ocupam $60 \%$ de uso; os documentários, 58\%; e os antivírus, 54\%, destacando-se também entre os itens de maior preferência.

${ }^{4}$ Revolico: É um site de anúncio utilizado para comercializar, promover negócios, permutar casas etc. 


\section{Artigo Completo}

Gráfico 2-Preferências de conteúdos digitais

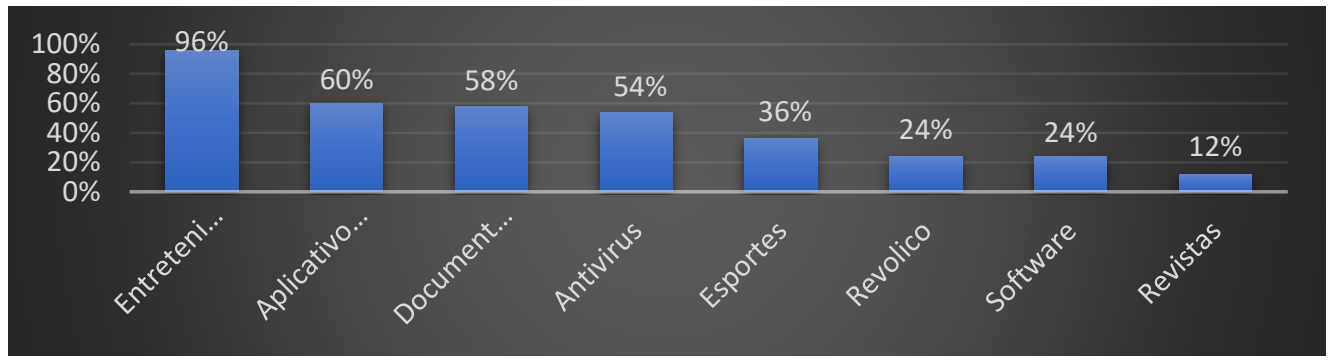

Fonte: Elaboração dos autores.

Devido à alta porcentagem dos usuários que preferem o entretenimento, 48 dos 50 entrevistados preferem o conteúdo audiovisual, como novelas, séries, filmes e reality shows. Uma questão que tratou da busca sobre o principal modo de obtenção das informações dos conteúdos digitais do PS foi incluída no questionário e apresenta seus resultados a seguir, de acordo com o gráfico 3.

Gráfico 3-Modo de obtenção dos conteúdos digitais

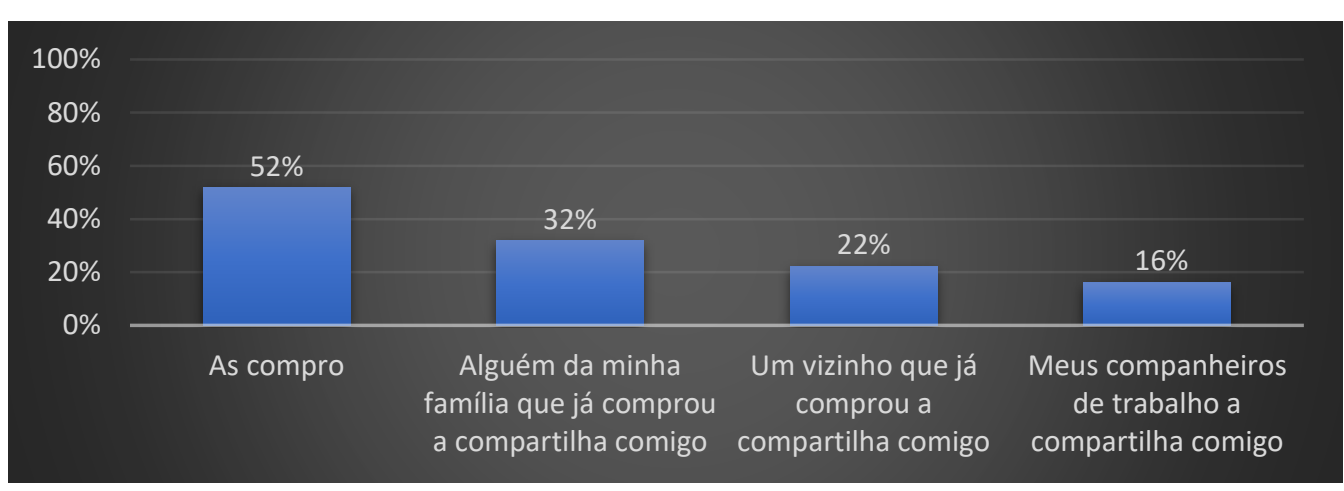

Fonte: Elaboração dos autores.

Constatou-se que $52 \%$ dos entrevistados adquirem as informações de que necessitam por meio da compra. Ainda assim, $70 \%$ as recebem por via de compartilhamento, descrito em $32 \%$ que obtém por alguém da família que realizou a compra, $22 \%$ de algum vizinho que comprou e $16 \%$ alegam receber as informações por meio de compartilhamento no trabalho. Constata-se, ainda, que os usuários que compram as informações as adquirem por compartilhamento. Deduzse que o método de compartilhamento entre os consumidores do PS gera a interação e estabelece uma rede social entre a população. Os usuários foram questionados sobre a frequência de uso dos conteúdos digitais.

Gráfico 4-Tempo de consumo do PS

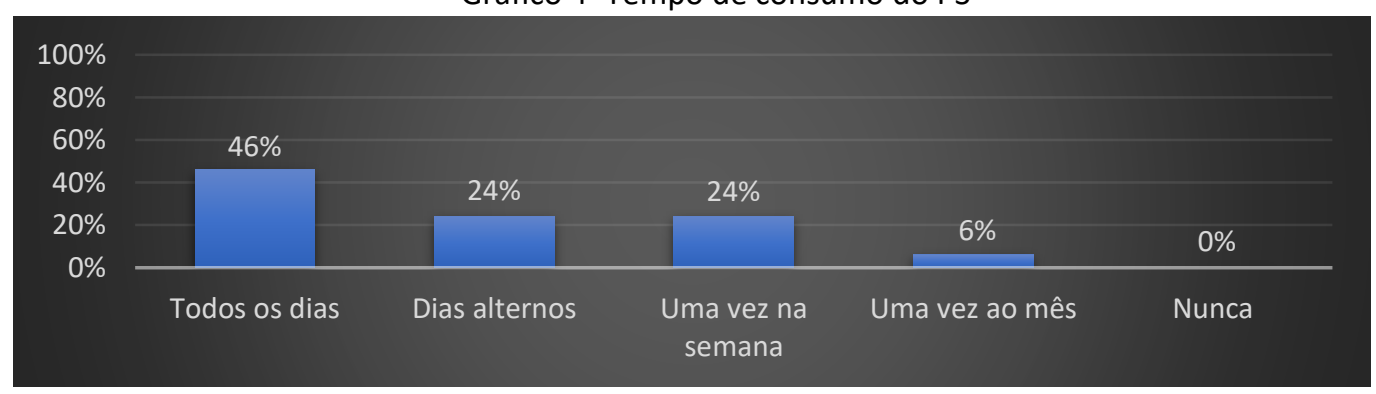

Fonte: Elaboração dos autores. 
Conforme identificado no gráfico 4, todos os entrevistados alegam usar os conteúdos digitais ao menos uma vez por mês. Sendo assim, $46 \%$ afirmam usar o PS todos os dias, $24 \%$ acessam em dias alternados, restando apenas $6 \%$ que disseram utilizar uma vez por mês. A maioria dos entrevistados, portanto, acessa ao menos uma vez por semana, representando $94 \%$ da amostra selecionada. A alta porcentagem de acesso ao PS demostra que o consumo dos conteúdos digitais é realizado com frequência regular. Entre as preferências por televisão nacional ou por audiovisual do PS, o resultado é apresentado no gráfico 5.

Gráfico 5-Preferências entre a televisão e o PS

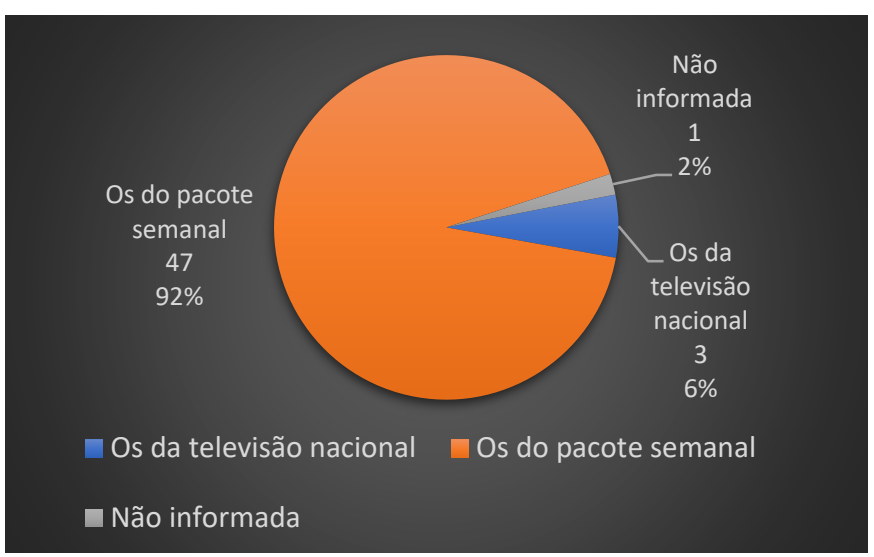

Fonte: Elaboração dos autores.

Os programas do pacote semanal têm ampla vantagem de preferência dos entrevistados quando comparados com os programas da televisão nacional, visto que $94 \%$ asseguram preferir os conteúdos do pacote, somente $6 \%$ optam pela televisão nacional. A oferta e a qualidade dos serviços de programação de audiovisuais na televisão nacional não cumprem as expectativas da população, por isso, os indivíduos procuram no pacote o que não conseguem por vias formais. Quanto ao serviço prestado, observa-se que apenas $2 \%$ dos entrevistados disseram não estar satisfeitos. Em contraposição, $80 \%$ afirmam estar satisfeitos com o atendimento dos vendedores, conforme apresentado no gráfico 6.

Gráfico 6 - Satisfação do serviço

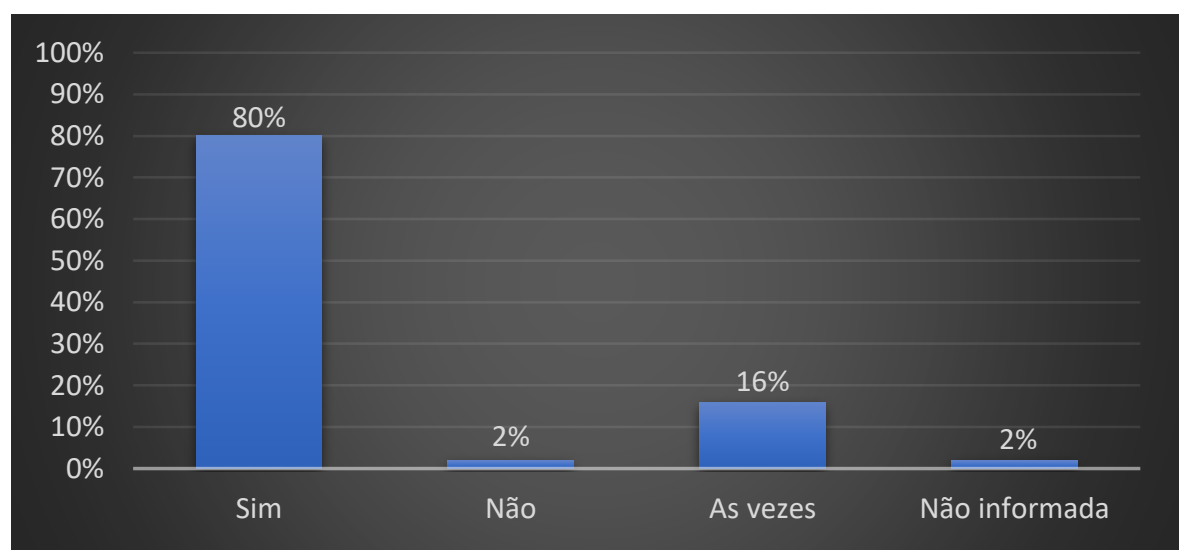

Fonte: Elaboração dos autores.

De acordo com os dados obtidos, os vendedores do PS empregam estratégias de design de serviços para ganhar e preservar os clientes. Visando à compreensão do funcionamento do 
processo de vendas do pacote, questionou-se sobre a seleção dos provedores do PS e a escolha dos usuários. Junto a isso, procuraram-se observar as características dos serviços prestados pelos vendedores. Foram combinados elementos positivos e negativos e determinadas nove alternativas para serem eleitas, a saber:

- Falta de educação na saudação.

- Caráter amável e boa atenção.

- Não me vendem a informação que desejo.

- Rapidez no serviço.

- Pouco conhecimento sobre a informação que estou comprando.

- Sugestões de informações que podem me interessar.

- Maus-tratos na relação interpessoal.

- Engano ao retornar meu pendrive.

- Demora ao vender-me a informação.

Além destas expressões do serviço, os entrevistados tiveram a possibilidade de sugerir outras que não se encontraram entre as apresentadas. 0 gráfico 7 indica o resultado desta questão.

Gráfico 7 - Características do serviço

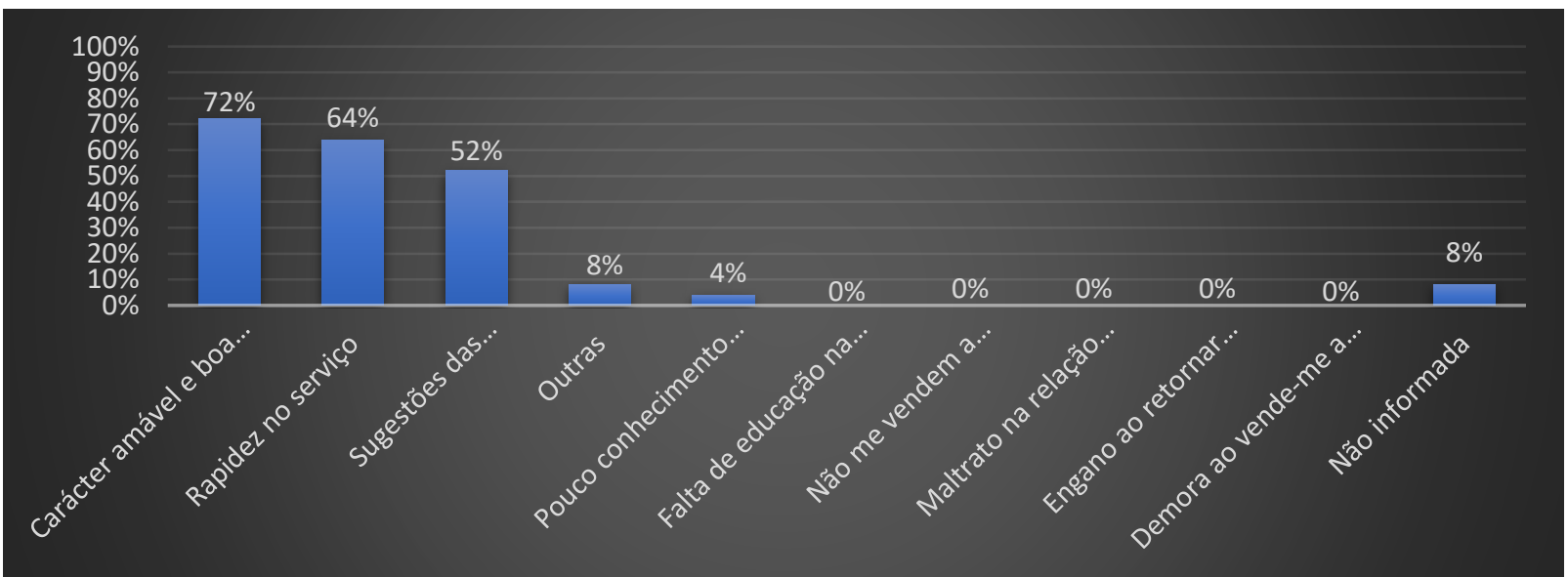

Fonte: Elaboração dos autores.

Três opções se destacaram dentre as características da prestação de serviço encontradas na compra do pacote semanal: caráter amável e boa atenção (72\%), rapidez no serviço (64\%) e sugestões das informações que podem gerar interesse (52\%). Os valores não totalizam $100 \%$ porque era permitido que o entrevistado indicasse mais de uma característica. Observa-se que, de nove variantes dadas, três delas eram positivas e o restante, negativas. Não obstante, as maiores porcentagens estiveram nos pontos favoráveis do serviço. Por conseguinte, e tendo em conta as respostas das questões anteriores, pode se dizer que os vendedores do PS se preocupam em garantir que as experiências dos clientes ao interagir com o serviço sejam agradáveis e satisfatórias. 
Gráfico 8-Relação custo-benefício

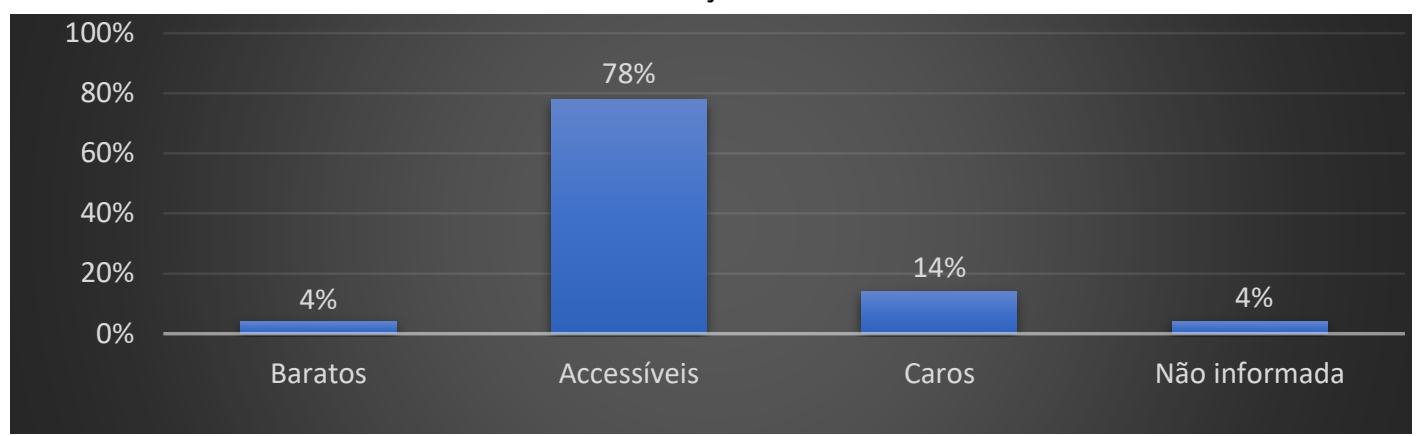

Fonte: Elaboração dos autores.

Percebe-se que $78 \%$ dos entrevistados consideram os preços da venda acessíveis, tendo em conta o custo-benefício, $14 \%$ julgam caro, $4 \%$ acham baratos e $4 \%$ preferiram não responder a questão, o que representa duas pessoas. As respostas obtidas permitem definir que os clientes/usuários do PS consideram justos os preços que pagam pelas informações de que precisam, o que explica que procurem tais conteúdos informacionais no pacote e não acessando a internet. Por fim, considerando o caráter holístico do serviço estabelecido entre os vendedores do PS como provedores e os clientes usuários, foi investigada a questão sobre a solicitações de informações por parte dos usuários para seus provedores. O gráfico 9 apresenta os resultados correspondentes à questão.

Gráfico 9-Solicitação de informação

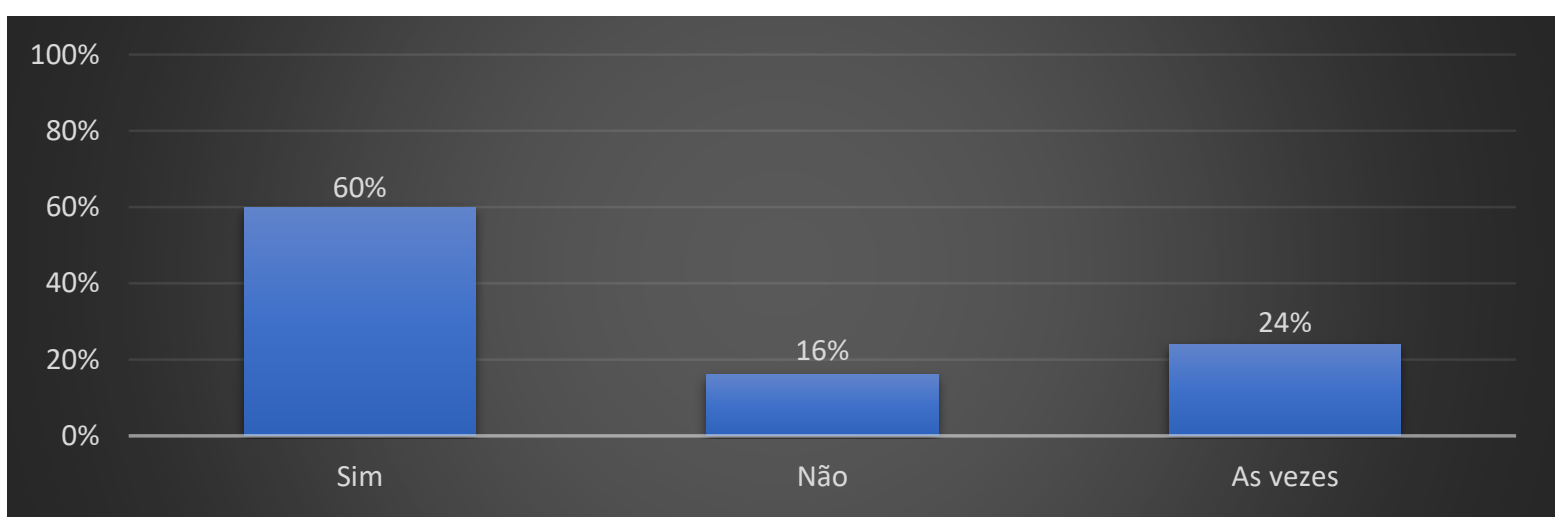

Fonte: Elaboração dos autores.

Entende-se que $84 \%$ dos entrevistados afirmam solicitar ao seu provedor quando não encontram alguma informação no pacote semanal. Esses dados gerias indicam que $60 \%$ dos usuários pedem as informações que desejam, $24 \%$ dizem que só o fazem às vezes e $16 \%$ afirmam que não solicitam informações. Desta forma, o serviço gerado pela comercialização e venda do PS possui uma forma holística, composta pelas necessidades e preferências informacionais dos clientes. 


\section{Considerações Finais}

O uso das TICs representa uma variação considerável na sociedade, uma mudança na educação, nas relações interpessoais e na forma de difundir e gerar conhecimentos. $O$ desenvolvimento tecnológico é uma prioridade na comunicação hoje e a limitação de acesso representa uma importante diferença entre países desenvolvidos e em desenvolvimento. As limitações de acesso à internet em Cuba impulsionaram a sociedade cubana a procurar vias e soluções para suas necessidades informacionais e comunicacionais, fazendo com que surjam modos alternativos de tecnologias e, com elas, novos negócios. Além de forçar o empreendedorismo, as startups e pessoas sem formação em design aplicam, intuitivamente, ferramentas atribuídas ao design de serviços na criação, comercialização e venda deste produto digital, que é o PS. A distribuição e circulação deste pacote semanal em Cuba têm criado espaço para a interação e a troca de informações entre as pessoas. Esta situação possibilitou a ocorrência da modificação da cultura, devido às mudanças nas tradições, estilos de vida, costumes, gostos, interesses e linguagem, entre outras.

É possível afirmar que as lacunas existentes na programação oficial da televisão cubana, no que concerne aos meios de comunicação, impõem necessidades por parte da população que adquire o pacote semanal. A falta de acesso à internet também acarreta lacunas em diversos sentidos por parte da população estudada, convertendo-se, assim, o OS em um forte competidor da empresa de telecomunicações, que é responsável pelo funcionamento da internet no país. O PS como negócio e gerador de serviços emprega as ferramentas do design de serviços, pois é um produto focado no usuário e que leva em consideração a forma como o mesmo vai consumir ou interagir com a informação, além de buscar a satisfação de suas necessidades e desejos, solucionando a carência informacional de maneira eficiente e eficaz.

Uma das vantagens do PS é que o usuário pode acessar as informações com relativa facilidade, estabelecendo trocas com vizinhos, amigos e colegas de trabalho e/ou colegas de escola ou, mesmo, empregar uma das vias aqui apresentadas para obtê-lo. Para a determinação dos conteúdos digitais do pacote semanal, os criadores usam como ferramentas a cocriação e o design de serviços, na conversão de um negócio popular ,como forma de pensar na melhor oferta de serviços e na garantia da boa qualidade do produto, o que, por si, já representa um reflexo da construção social deste fenômeno. 


\section{Referências}

Concepción, J. R. Escaneando el Paquete Semanal (I) (+ Infografía). In: Cubadebate, 2015a. (http://www.cubadebate.cu/noticias/2015/10/19/el-paquete-semanalinfografia/\#.WCFdR9LhDIU)

Concepción, J. R. Escaneando el Paquete Semanal (II). In: Cubadebate, $2015 b$. (http://www.cubadebate.cu/temas/cultura-temas/2015/10/20/el-paquete-semanal-ii/)

Consejo Popular - EcuRed. In: < https://www.ecured.cu/Consejo_Popular >. Acesso em: 17 nov. 2017.

Maranão, A. C. K. O jornalismo brasileiro: convergencia e mudança provocadas por las Tecnologias da Informação e Comunicação.1.ed. Brasília. U. de Brasília:Ed. 360, (2017).

Stickdorn, M.; Schneider, J. This is service design thinking. Basics, Tools, Cases. Amsterdam. BIS Publishers: Ed, 2011.

Telecomunicaciones|MINCOM.In:MINCOM,2018.(http://www.mincom.gob.cu/?q=telecomunicaci ones) 